\begin{tabular}{|c|c|}
\hline \multicolumn{2}{|c|}{ Advertisers in This Issue } \\
\hline${ }^{*}$ Aldrich Chemical Company, Inc. & 54 \\
\hline${ }^{*}$ American Institute of Physics & 64 \\
\hline${ }^{*}$ Amptek Inc. & 33 \\
\hline Annual Reviews & 73 \\
\hline Arizona State University & 7 \\
\hline Axic, Inc. & 58 \\
\hline${ }^{\star}$ Bio-Logic Science Instruments & 20 \\
\hline * Cambridge University Press & 101 \\
\hline * Cerac Inc. & 76 \\
\hline Chemat Technology, Inc. & 47 \\
\hline * Digital Instruments & 10 \\
\hline * Edax International Inc. & 14,15 \\
\hline ^ Elsevier Science & 84 \\
\hline * ESM Software & 53 \\
\hline * Gordon \& Breach & 82 \\
\hline${ }^{*}$ Hinds Instruments, Inc. & 7 \\
\hline " High Voltage Engineering & inside front cover \\
\hline ऋ Huntington Laboratories & outside back cover \\
\hline ॠ JEOL USA, Inc. & 16 \\
\hline${ }^{*}$ Lambda Technologies Inc. & $\overline{26}$ \\
\hline “ MDC Vacuum Products Corporation & 25 \\
\hline The Mellen Company, Inc. & 73 \\
\hline${ }^{\star}$ MMR Technologies, Inc. & 20 \\
\hline${ }^{\star}$ Nanopowder Enterprises Inc. & $\overline{11}$ \\
\hline${ }^{\text {* National Electrostatics Corporation }}$ & 9 \\
\hline New Focus, Inc. & inside back cover \\
\hline * NFT-Nanofilm Technology & 64 \\
\hline${ }^{*}$ Omicron Associates & 31 \\
\hline ॠ Osmic, Inc. & 24 \\
\hline Outokumpu Research Oy & 13 \\
\hline Oxford Cryosystems & 17 \\
\hline * Oxford University Press & $\overline{102}$ \\
\hline${ }^{\text {" Park Scientific Instruments }}$ & 1 \\
\hline${ }^{*}$ Philips Analytical X-Ray & 23 \\
\hline * Plenum Publishing Corporation & 74 \\
\hline * Praxair Specialty Ceramics & 21 \\
\hline${ }^{\text {* Princeton Gamma-Tech Inc. }}$ & 18 \\
\hline * Quad Group & 27 \\
\hline * Quantum Design & 8 \\
\hline * Solartron & 2 \\
\hline 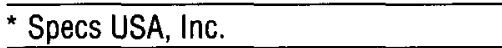 & 78 \\
\hline * Springer-Verlag & 77,100 \\
\hline${ }^{\star}$ Structured Materials Industries, Inc. & 11 \\
\hline * Sycon Instruments & 6 \\
\hline "VAT, Inc. & 12 \\
\hline${ }^{\star}$ Virginia Semiconductor, Inc. & 32,79 \\
\hline VLSI Standards Inc. & 78 \\
\hline *Voltaix, Inc. & 28 \\
\hline $\begin{array}{l}\text { * Please visit us at the Exhibit, December 2- } \\
\text { MRS Fall Meeting in Boston. }\end{array}$ & the 1997 \\
\hline $\begin{array}{l}\text { For free intormation about the products and servi } \\
\text { and mail the Reader Service Card, or FAX it to } 31\end{array}$ & $\begin{array}{l}\text { red in this issue, fill out } \\
165 .\end{array}$ \\
\hline
\end{tabular}

\section{New Solutions}

\section{Materials and Surface Analysis}

\section{SNOM - The New Dimension in Optical Resolution}

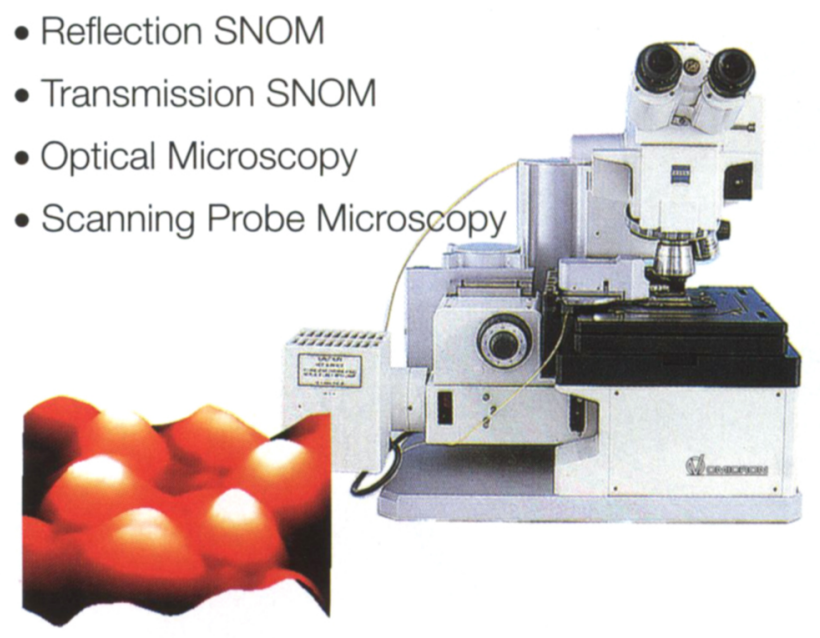

\section{ESCAPROBE - Surface Analysis and Materials Research System}

\section{- Uncompromised ESCA Performance \\ - Compact System Solution \\ - Easy to use}
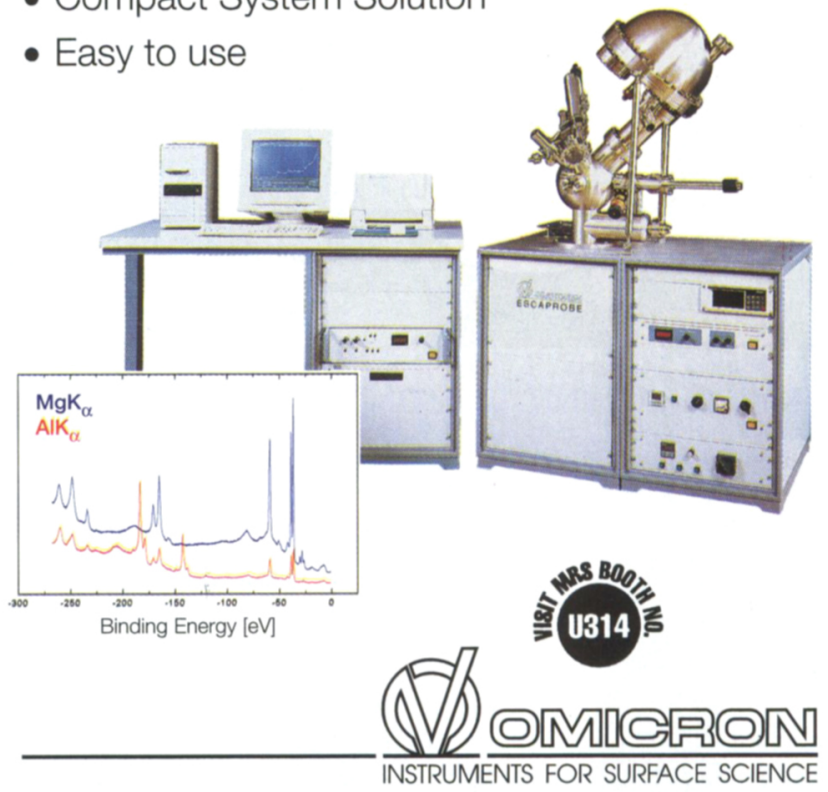

Headquarters:

OMICRON VAKUUMPHYSIK GMbH

USA:

Idsteiner Str. 78

D-65232 Taunusstein, Germany

Tel. +49 (0) 6128 987-0

Fax +49 (0) 6128 987-185

OMICRON Associates

1226 Stoltz Road

Bethel Park, PA 15102

Tel. (412) 831-2262

Fax (412) 831-9828

http://www.omicron-instruments.com/ 


\section{"But still try-for who knows what is possible?"}

- Michael Faraday

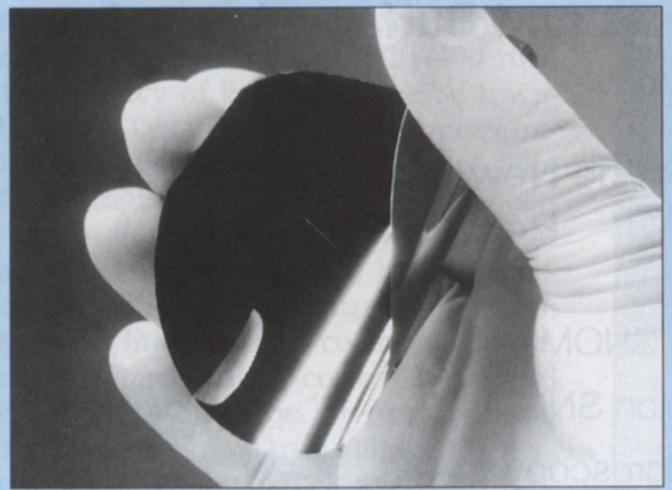

10-MICRON THICK SILICON WAFER

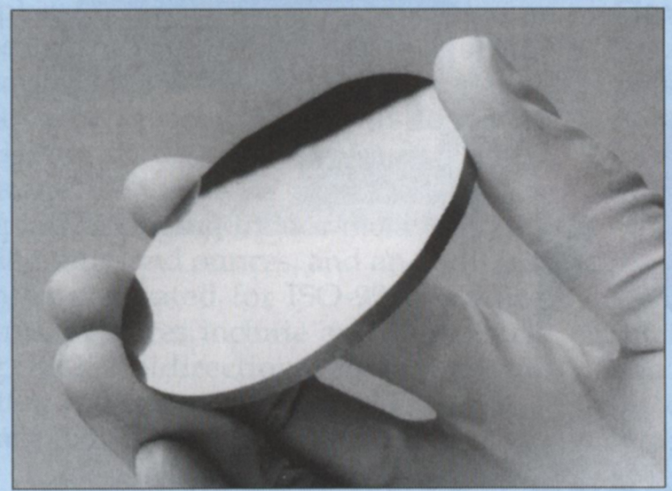

4000-MICRON THICK SILICON WAFER

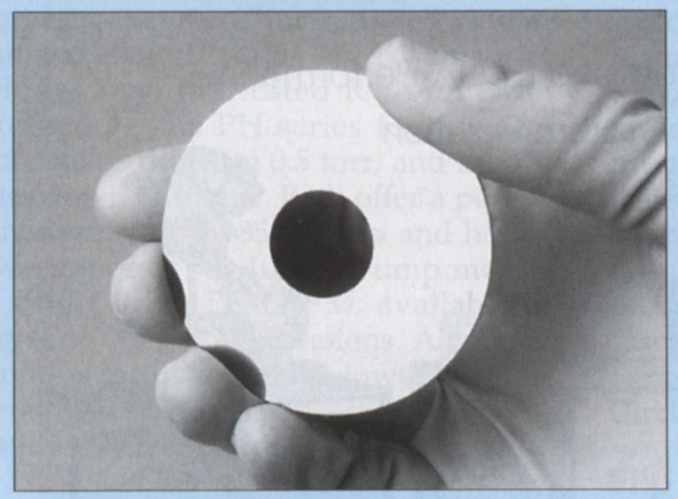

MICROMACHINED SILICON WAFER

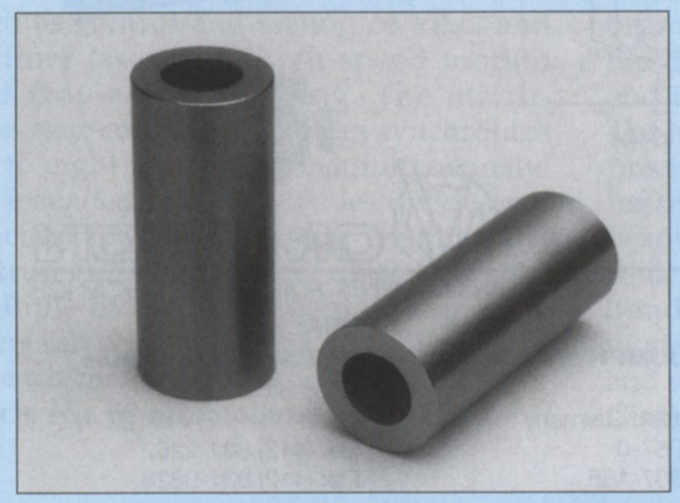

The ubiquitous nature of single crystal silicon provides for application possibilities which go far beyond those defined by the "traditional" microelectronics industry. Virginia Semiconductor, Inc. considers silicon to be an ENGINEERED MATERIAL ideal for a host of applications that call for

- fatigue and chemical resistance

- machinability

- mechanical robustness

- thermal stability

- and electrical conductivity.

When it comes to preparing engineered silicon products, we have frequently stated (with tongue in check), "if we can't make it, you don't need it!"

In the final analysis, we are most eager to IMAGINE, to be CHALLENGED, and to TRY. At Virginia Semiconductor, Inc., we think of the possibilities-not the limitations. Those who know us now expect nothing less; why shouldn't it be that way in our service to you?

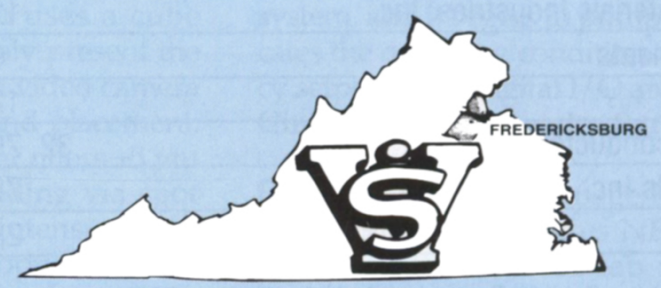

Virginia Semiconductor Inc. 1501 Powhatan Street

Fredericksburg, VA 22401

Phone: (540) 373-2900 Fax: (540) 371-0371 
APPLICATIONS

- X-Ray Detection

- Fluorescence

- Environmental Monitors

- Nuclear Medicine

- Portable Instruments

- Space \& Astronomy

- Teaching and R\&D

\section{FEATURES}

- Solid State Design

- Thermoelectric Cooler

- Hermetic Package

- Wide Detection Range

- Beryllium Window

- Easy to Operate

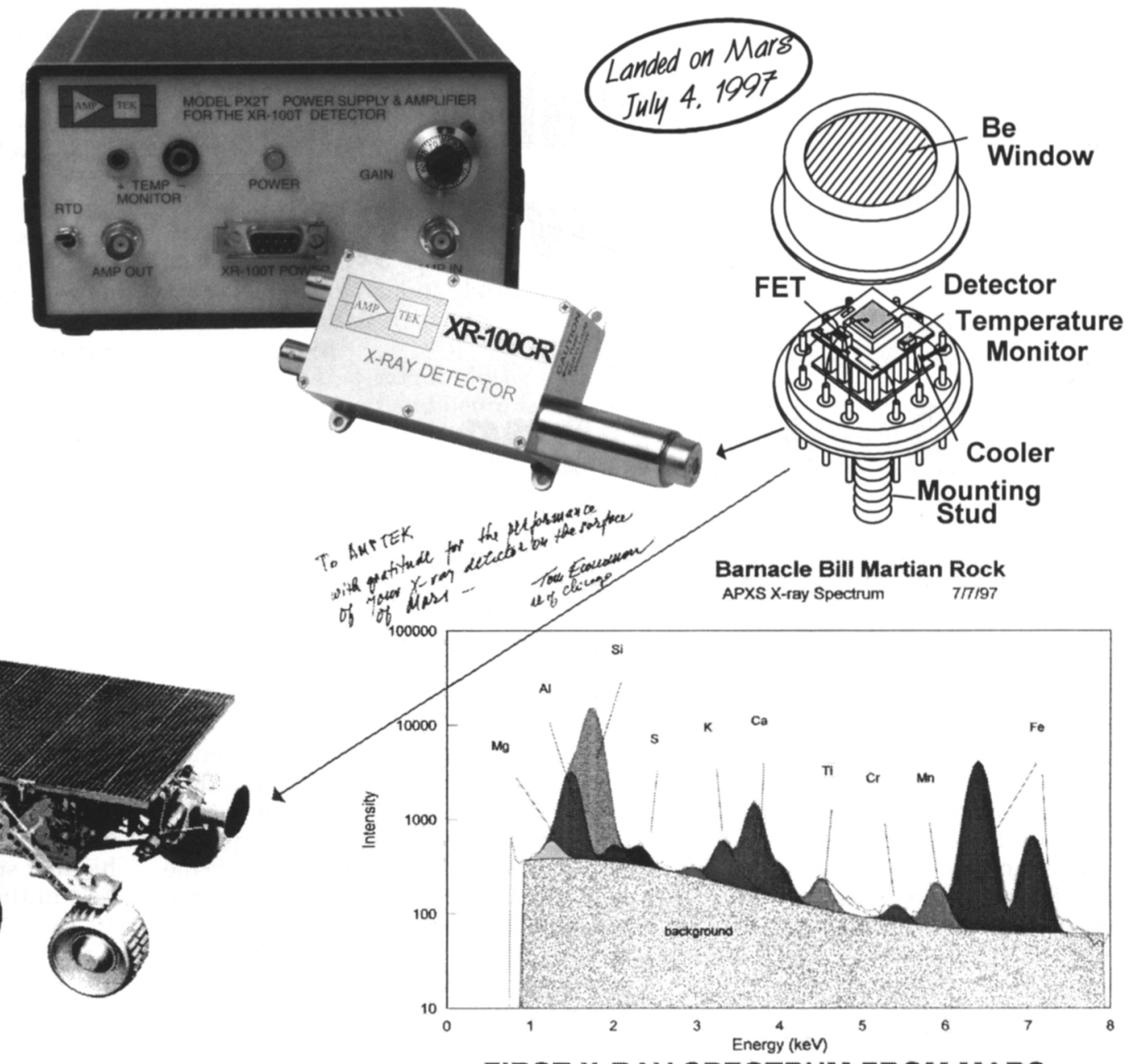

FIRST X-RAY SPECTRUM FROM MARS

For its unique design and reliability, this detector was selected for the Mars Pathfinder Mission and placed on the Rover arm to perform rock and soil analysis via $x$-ray fluorescence techniques.

NEW!!!

$196 \mathrm{eV}$ Resolution XR-100CR

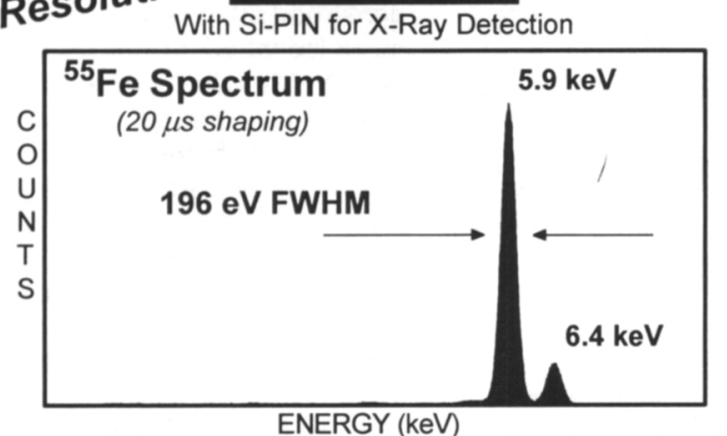

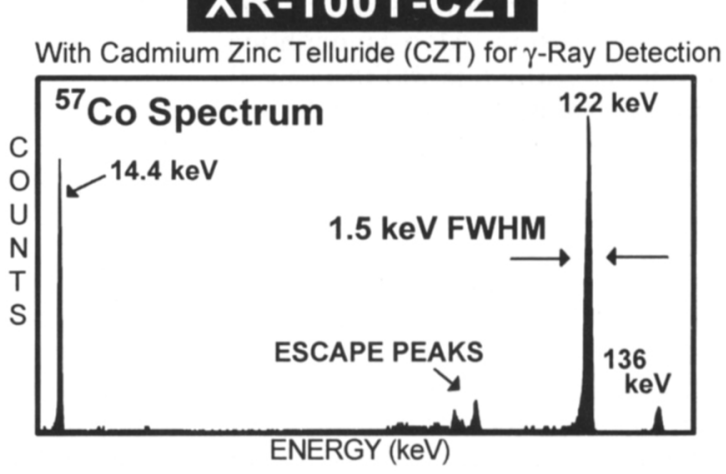

Models XR-100CR and XR-100T-CZT are high performance X-Ray and $\gamma$-Ray detectors mounted on a thermoelectric cooler together with the input FET to the Preamplifier. Monitored by an integrated circuit, these components are kept at $-30^{\circ} \mathrm{C}$ and are enclosed in a hermetic TO-8 package with a vacuum tight, light tight Beryllium window. Power and signal processing to the detector is provided by the PX2T in order to ensure quick, stable operation in less than one minute from power turn-on. The output pulse produced by the PX2T can be connected directly to the input of a Multichannel Analyzer (MCA). For optimum portability and versatility, use the Amptek MCA8000A "Pocket MCA."

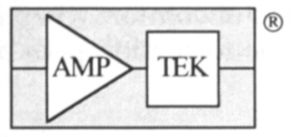
AMPTEK INC. 6 DE ANGELO DRIVE, BEDFORD, MA 01730-2204 U.S.A. Tel: +1 (781) 275-2242 Fax:+1 (781) 275-3470 e-mail: sales@amptek.com

